\title{
A NATUREZA DO ESPAÇO NUMA PERSPECTIVA COMUNICATIVA OU PÚBLICA
}

\author{
THE NATURE OF SPACE IN THE PERSPECTIVE COMMUNICATIVE OR PUBLIC \\ LA NATUREZA DEL ESPACIO EM UNA PERSPECTIVA COMUNICATICA O PÚBLICA \\ Rosalvo Nobre Carneiro - Universidade Federal de Pernambuco \\ rosalvonobre@uern.br
}

\begin{abstract}
Resumo
Pretende-se discutir sobre a natureza do espaço e, baseando-se na Teoria da Ação Comunicativa de Jürgen Habermas e em aportes teórico-metodológicos miltonianos, propô-la como sendo comunicativa ou pública. A natureza do espaço, que em sua totalidade é instrumental-privada e comunicativa-pública, é analisada a partir das suas interações, de um lado, com o uso humano da técnica, do tempo, da razão e da emoção e, de outro, pelas interações entre forma, função, processo e estrutura. Do modo intersubjetivo como ocorrem estas interações, resulta a natureza comunicativa ou pública do espaço. 0 espaço comunicativo ou público apóia-se na razão comunicativa e nas ações orientadas para o entendimento mútuo livre de coerções. Neste sentido, contrapõe-se à natureza instrumental do espaço, fundamentada na razão cognitivo-instrumental e nas ações orientadas para fins dominantes na atualidade e associada à colonização do mundo do sistema sobre o mundo vivido.
\end{abstract}

Palavras-chave: Natureza do espaço. Teoria da ação comunicativa. Espaço público.

\begin{abstract}
The aim is to discuss the nature of space and, based on the Theory of Communicative Action, Jürgen Habermas and contributions in theoretical and methodological miltonianos, propose it as communicative or public. The nature of space, which is instrumental in its entirety private-and public-communicative, is analyzed from its interactions, on one side, with the human use of the technique, time, reason and emotion, with the interactions between form, function, structure and process. In the way intersubjective these interactions occur as a result communicative nature or the public space. The space communicative or public support in the communicative reason and actions directed towards mutual understanding free from coercion, in this sense opposed to the instrumental nature of space, based on reason and cognitive-instrumental in the actions oriented purposes, dominant in actuality and colonization of the world associated with the system on the world lived.
\end{abstract}

Key-words: Nature of space. Theory of action communicative. Public space.

\section{Resumen}

Se tiene la intención de discutir la naturaleza del espacio y, sobre la base de la teoría de la acción comunicativa de Jürgen Habermas y en las contribuciones teóricas y metodológicas miltonianas, proponerla como siendo comunicativa o pública. La naturaleza del espacio, que en su totalidad es instrumental-privada y pública-comunicativa, se analiza a partir de sus interacciones, por un lado, con el uso humano de la tecnología, del tiempo, de la razón y de la emoción, y por otro lado, por la interacción entre forma, función, proceso y estructura. Del forma intersubjectiva de estas interacciones resulta la naturaleza pública o comunicativa del espacio. El espacio comunicativo o público se basa en la razón y la acción comunicativa orientada a la comprensión mutua libre de violencia, en este sentido diferente de la naturaleza instrumental del espacio, basado en la razón instrumental-cognitiva y la acción orientada a fines, la cual es dominante actualmente y está asociada con la colonización del mundo de lo sistema sobre el mundo vivido.

Palabras clave: Naturaleza de lo espacio. La teoría de la acción comunicativa. El espacio público.

\begin{tabular}{|l|c|c|c|c|c|c|}
\hline Boletim Goiano de Geografia & Goiânia - Goiás - Brasil & v. 29 & n. 1 & p. 33-46 & jan. / jun. & 2009 \\
\hline
\end{tabular}




\section{Introdução}

O modo como a técnica, o tempo, a razão e a emoção são utilizados pelos atores espaciais em um dado momento e lugar justifica a produção de uma natureza espacial determinada, baseada em formas, funções, processos e estruturas próprias, conforme a produção e reprodução do espaço seja público-comunicativa ou privada-instrumental.

O espaço comunicativo, sobre o qual se argumenta aqui sua produção e reprodução, funda-se no "princípio de universalização", segundo o qual "toda norma válida tem que preencher a condição de que as conseqüências e efeitos colaterais que previsivelmente resultem de sua observância universal, para a satisfação dos interesses de todo indivíduo possam ser aceitas sem coação por todos os concernidos" (HABERMAS, 2003, p. 147, grifo do autor).

Na primeira seção, discute-se como o espaço pode ser produzido e se reproduz em função da maneira como a técnica é utilizada pelos homens para atingirem seus propósitos. Nas seções seguintes, a mesma questão é abordada em função do uso do tempo, da razão e da emoção, respectivamente. Na última seção, argumenta-se sobre a proposição existencial de uma natureza comunicativa para o espaço, capaz de fundamentar sua produção e reprodução pública, a partir da análise da forma, função, processo e estrutura próprios a ela, contrapondo-a às questões da natureza instrumental espacial.

\section{0 espaço e o uso humano e social da técnica}

As técnicas são diferentes de tal modo que podem ser divididas em: em comunicativas, estratégicas e instrumentais. Os homens, as empresas e as instituições (SANTOS, 1985) como produtores do espaço, utilizam diferentes técnicas quando comparados entre si enquanto grupos que se orientam por propósitos comunicativos ou instrumentais, porém semelhantes enquanto coletividades que se guiam por propósitos idênticos.

A história sócio-territorial ocidental se caracteriza por um processo de transformação e avanço das técnicas instrumental e estratégica sobre a comunicacional e consequentemente, da hegemonia de uma natureza espacial orientada para a realização de fins próprios aos propósitos dos agentes econômicos e políticos em detrimento dos atores sociais que se orientam para o entendimento. 
O mercado e a política colonizam os mundos da vida (HABERMAS, 2003 , t. I) com suas ordens orientadas ao êxito em detrimento das ordens orientadas ao entendimento coletivo, próprio da técnica comunicacional que está a serviço da conquista da cidadania espacial (SANTOS, 2000). A técnica é abrangente das relações entre o mundo social, o mundo subjetivo e o mundo objetivo, das ações do homem sobre o homem e destes sobre a natureza (MARX; ENGELS, 2001).

\section{0 espaço, o uso humano e social do tempo e sua relação com o uso da técnica}

As técnicas, na medida em que intermedeiam a produção espacial pelo homem, o fazem normatizada temporalmente, da mesma forma que normatizam o tempo. Relacionada ao tempo, as técnicas não apenas resultam de um dado momento histórico como também em tempos empíricos, mediante a transformação que operam no espaço e sua cristalização na paisagem em objetos (SANTOS, 1999) ou como normas que se coisificam (DURKHEIM, 2003).

As rugosidades, isto é, o tempo passado que permanece presente na paisagem em forma de objetos e no espaço na forma de ações (SANTOS, 1988) revela que tipo de técnica foi dominante em um dado período, bem como a que é hegemônica atualmente. Assim, as formas pretéritas e atuais, com suas velhas ou novas funções, se produzem e reproduzem por meio dos processos públicos ou privados advindos da estrutura social contemporânea.

Espaço e tempo são termos indissociáveis, porém são sempre diferenciais, desiguais e combinados (SMITH, 1988) em seus usos e re-produções, como bem o prova a existência de variadas regiões com suas múltiplas temporalidades, seus sistemas de objetos e ações. A construção dos espaços-tempos varia segundo a técnica dominante. Deste modo, se as técnicas operam a partir das ações orientadas a fim de dominarem, o espaço-tempo resultante estará a serviço de verticalidades (SANTOS, 1988) que buscam impor-se aos espaços-tempos cujas técnicas organizadas intersubjetivamente resistem enquanto contrafinalidades (SARTRE, 2002) à sua colonização (HABERMAS, 2003, t. II).

Por outro lado, quando as técnicas comunicativas são reinantes em um dado lugar, o espaço-tempo resultante estará a serviço das horizontalidades (SANTOS, 1999) e do entendimento a partir da utilização de atos de fala de validez criticáveis sobre as questões dos mundos subjetivo, social e 
objetivo que afetam uma comunidade de linguagem. Aqui, o espaço comunicativo-público (CARNEIRO, 2007) pode desenvolver-se em sua plenitude.

As complexas formas de utilização técnica nos diversos espaços-tempos e sobre eles revelam, por seu turno, a conformação de um espaço-tempo unificado, com base em razões instrumentais, ou unitário, baseado em razões comunicativas. Estas duas razões estão presentes espacialmente, todavia, em graus variáveis.

\section{0 espaço, o uso humano e social da razão e sua relação com o uso do tempo}

A hegemonia de uma dada forma de utilização do tempo pelo homem e pelas formações espaciais, em um dado momento e lugar, tem como dado explicativo a expansão de uma razão própria que impõe às coisas sua lógica existencial ou relacional, a partir de uma forma de pensar, cujo outro é sempre uma forma de agir.

A ocidentalização do mundo pode ser vista como um processo de racionalização ou a "[...] ampliação das esferas sociais, que ficam submetidas aos critérios de decisão racional" (HABERMAS, 1997, p. 45) advinda da razão instrumental, cujas características básicas são as relações sujeito-objeto, orientação da ação para o êxito e o domínio humano sobre a natureza.

Relacionada a esta forma de razão o espaço não pode ser outra coisa senão algo excludente e egocêntrico, ponto de partida e de chegada para a reprodução de formas de pensar cujos conteúdos do mundo sistêmico, simbolizados no dinheiro e no poder (HABERMAS, 1990), preenchem sua forma. Daí a importância do conceito de razão comunicativa ou intersubjetiva, amparada nas relações entre falantes e ouvintes que se orientam para o entendimento mútuo dentro de um contexto normativo de seus mundos vividos. Neste sentido, afirma Habermas (2003, t. I, p. 24, tradução nossa), “[...] a racionalidade tem menos a ver com o conhecimento ou com a sua aquisição do que com a forma como os sujeitos capazes de linguagem e ação fazem uso dele". Contrariamente à instrumental, a racionalidade comunicativa produz um espaço-tempo includente e partilhado intersubjetivamente em que há a produção e reprodução, agora, das formas de pensar cujos conteúdos advêm do mundo vivido, valorizando a proximidade, a co-presença e as ações de entendimento gerador do consenso liberto de ações estratégicas.

O projeto de modernidade desenrolou-se para a eliminação dos conteúdos emocionais ou afetivos do homem e da humanidade ao reificar a razão instrumental. Cabe, portanto, perceber as relações entre emoção e espaço 
por intermédio do uso humano da razão, a fim de perceber como a natureza comunicativa espacial se produz neste contexto.

\section{0 espaço, o uso humano e social da emoção e sua relação com o uso da razão}

A divinização da razão instrumental contribuiu para que a informação, particularmente científica, se associasse à técnica moderna para conformar, desse modo, os pilares de sustentação da própria modernidade. O oposto deste processo foi a colonização dos lugares organizados em torno da comunicação e, portanto, da emoção, por esta mentalidade ocidental nascida como o capitalismo.

A crise de legitimação da modernidade, contemporânea da crise social, humana e material propiciada pelo sistema social que the deu e dá sustentação, contribuiu para que o seu outro, a que poderíamos chamar pósmodernidade, se fortalecesse, isto é, a própria sociedade, o homem e o espaço, porém sob bases intersubjetivas.

Pensar, portanto, na emoção como conteúdo comunicativo do espaço é atentar para o fato de que ele, jamais ausente, ganha importância na atualidade, em função da própria crítica social aos fundamentos da modernidade e aos seus propósitos humanitários até agora não alcançados. Uma parcela significativa da sociedade se organiza hoje em torno de ações cuja emoção se sobrepõe à razão instrumental, passando a advogar um uso comunicativo para a razão que aparece, assim, como uma norma de fala e ação para falantes e ouvintes que partilham o mesmo mundo da vida.

Como lembra Habermas (2003, p. 70), “manifestamente, os sentimentos têm, relativamente à justificação moral das maneiras de agir, um significado semelhante ao que as percepções têm para a explicação teórica de fatos". Os grandes temas sociais são exemplares, pois permitem que os atores sociais, não apenas locais, se aproximem a partir de uma linguagem que é fundamentalmente emocional.

0 espaço, os sistemas de objetos e os sistemas de ações orientadas para o entendimento e para fins

A coabitação é condição necessária da convivência humana, podendo manifestar-se como coabitação do consenso e coabitação da coerção de clas- 
se (MOREIRA, 2006). Destas duas lógicas convivenciais organiza-se o espaço e advém sua natureza total contemporânea, isto é, subjetivo e intersubjetivo, instrumental e comunicativo, privado e público.

A natureza do espaço, conforme Carneiro (2006), é ser formada por um sistema de objetos e um sistema de ações (SANTOS, 1999) orientadas para fins e/ou para o entendimento mútuo (HABERMAS, 1990) enquanto uma totalidade em constante processo de totalização (SARTRE, 2003). Esta dinâmica contraditória e solidária do espaço tem sua matriz nas interações entre agentes e atores sociais que produzem o espaço a partir de racionalidades a ações semelhantes e diferentes, solidárias e contrastantes. As intencionalidades que presidem no movimento socioespacial são, em cada caso, a condição e o resultado de formas de pensar, falar e agir.

O espaço, sua produção e reprodução e, portanto, sua natureza deve ser buscados no processo de colonização do mundo vivido, partilhado intersubjetivamente pelo mundo sistêmico (HABERMAS, 2003, t. II) e seus signos, o dinheiro e o poder, posto que as verticalidades impõem às horizontalidades, ao lugar e ao cotidiano de todos, sua razão e ações instrumentais, cujas razão e ações comunicativas aparecem como contra-racionalidade e contra-finalidades.

Pensar a natureza do espaço numa perspectiva comunicativa ou pública significa admiti-la como sendo formada por um sistema de objetos e um sistema de ações orientados para o entendimento, cujas interações intersubjetivas, a razão e as ações comunicativas, o consenso livre de coerção e o mundo vivido se sobressaem sobre os elementos do mundo sistêmico. Nesta perspectiva, seria possível vislumbrar a emergência do período demográfico (SANTOS, 1985) ou, na linguagem de Moreira (2006, p. 74), a valorização da coabitação humana do consenso frente à coabitação da coerção espacial.

O espaço comunicativo, cuja intencionalidade de sua produção e reprodução se orienta para a realização plena da cidadania, se configura por um sistema de objetos enquanto formas, cujas funções são publicamente construídas por intermédio de um sistema de ações guiadas pelos processos de entendimento mútuo, gerador do consenso racionalmente motivado sobre as questões presentes na estrutura de seus mundos vividos e sistêmicos (CARNEIRO, 2007).

Consoante Santos (1985, p. 52), "forma, função, estrutura e processo são quatro termos disjuntivos, mas associados, a empregar segundo um contexto do mundo de todo dia". A interação ou agir social enquanto "[...] a solução para um problema de coordenação: como coordenar entre si dos 
planos de ação de vários atores, de tal modo que as ações de Alter possam ser engatadas nas de Ego?" (HABERMAS, 1990, p. 70, grifos do autor) aparece aqui como a condição e o resultado de suas associações, garantindo que as partes conformem o todo.

\section{As formas socioespaciais e sua produção e reprodução humana e social}

Forma é o aspecto visível de uma coisa (SANTOS, 1985, p. 50), de tal modo que a forma comunicativa ou pública de um dado espaço é a expressão visível do "princípio da universalização" ou princípio moral, e tal visibilidade ou sua fundamentação expressa o conteúdo normativo de formação da vontade com base no "discurso prático" (HABERMAS, 2003, p. 149), isto é, “[...] a forma de argumentação em que se convertem em tema as pretensões de correção normativa" (HABERMAS, 2003, t. II, p. 38, tradução nossa).

A forma instrumental ou privada, por sua vez, expressa o princípio subjetivo de formação da vontade sobre os pontos de vista da pluralidade dos atores com base no "discurso teórico", entendido por Habermas (2003, t. II, p. 38, tradução nossa) como “[...] a forma de argumentação em que se convertem em tema as pretensões de verdade que se tornaram problemáticas". Esta visibilidade é fundamental para o processo de reprodução socioespacial de uma dada forma, uma vez que atinge os atores sociais que estão adotando a perspectiva descritiva do espaço na terceira pessoa, isto é, observando "[...] o modo como um ator atinge um objetivo através de uma atividade orientada para um fim, ou como ele, através de um ato de fala, chega a um entendimento com alguém sobre algo" (HABERMAS, 1990, p. 65).

A reprodução das formas the confere a condição de fator social, ou seja, de objeto que exerce influência sobre as ações humanas, e como tal apresenta a capacidade de lhes opor resistência, interferindo em seus propósitos. Esta resistência se dá sobre o agir estratégico ou instrumental, posto que a reprodução sócio-territorial das formas comunicativas ou públicas é o resultado prático da reprodução da interação social.

Por outro lado, a forma também corresponde a um "arranjo ordenado de objetos" (SANTOS, 1985, p. 50), ao qual se acrescentará o arranjo interativo de falantes e ouvintes, organizado segundo uma lógica que já é representativa da função requerida e permitida por esta mesma forma. Dis- 
tinguir-se-á, assim, um arranjo interativo sistêmico, vertical, hierarquizado e funcionalmente integrado, próprio do Estado, seja democrático ou ditatorial, ou do mercado, de um arranjo interativo comunicativo, horizontal e nãohierarquizado e socialmente integrado, típico do mundo vivido.

No arranjo interativo de falantes e ouvintes, estes se organizam em torno de três perspectivas de descrição dos "proferimentos lingüísticos" ou "[...] atos através dos quais um falante gostaria de chegar a um entendimento com um outro falante sobre algo no mundo" e das 'atividades não-linguísticas' ou atividades orientadas para um fim “[...] através das quais um ator (Aktor) intervém no mundo, a fim de realizar fins propostos, empregando meios adequados" (HABERMAS, 1990, p. 65).

Assim, conforme Habermas (1990, p. 65), há a descrição da primeira pessoa, cuja perspectiva do agente ou ator social é assumida, da segunda pessoa, que necessita de contextos cooperativos, e a da terceira pessoa na qual alguém observa o modo como um agente ou ator social atinge o seu objetivo por meio de ações não-linguísticas ou chega a um entendimento com outro, através de proferimentos lingüísticos.

Em formas comunicativas ou públicas, a exemplo de escolas, cujas instituições de sua comunidade funcionam democraticamente, ou de associações de bairros, as perspectivas das primeiras e segundas pessoas são hegemônicas, pois a intersubjetividade dos atos de fala são normativos, ao passo que nas formas instrumentais ou privadas, a exemplo de empresas multinacionais, domina a terceira, pois a subjetividade é a norma de suas ações. Estas diferenciações de domínio da intersubjetividade e da subjetividade já apontam para as relações das formas com suas funções públicas ou privadas.

\section{As funções socioespaciais e suas relações com as formas}

A função sugere uma atividade esperada de uma forma (SANTOS, 1985, p. 50) de tal maneira que de um indivíduo determinado é possível esperar uma atuação social orientada pelas regras, de uma família determinada, um bom relacionamento entre pai, mãe e filho, de uma escola, a gestão democrática, de uma empresa, a lucratividade com custo ambiental, das câmaras e assembléias legislativas, a fiscalização dos atos executivos, da Organização das Nações Unidas, a manutenção da paz mundial.

Está em jogo, portanto, relações diretas entre responsabilidade e autonomia humana e social, assim, no caso da produção e reprodução do es- 
paço público comunicativo "um grau maior de racionalidade comunicativa amplia, dentro de uma comunidade de comunicação, as possibilidades de coordenar as ações sem recorrer à coerção e de resolver consensualmente os conflitos de ação [...]" (HABERMAS, 2003, t. I, p. 33, tradução nossa).

Cada forma, comunicativa/pública ou instrumental/privada, pode ou não abranger mais de uma função (SANTOS, 1985, p. 51), seja uma função comunicativa ou pública, ou função instrumental ou privada, a exemplo de escolas e universidades particulares e de empresas estatais. Nos dois primeiros casos, tem-se uma função primordial ou lucrativa, seguida de outra função secundária ou social, já no último, tem-se uma função social, seguida por outra lucrativa.

Uma dada função se diferencia, comunicativa ou instrumentalmente, de intencionalidades sociais ou particulares da forma criada para contê-la. Escolas estatais ou particulares apresentam objetivos sociais, logo suas funções são comunicativas. Todavia, a intencionalidade de ambas difere, assim, no primeiro caso permanece a busca do entendimento e no segundo, do êxito. A intencionalidade advém diretamente dos processos socioespaciais e, neste sentido, se inter-relacionam com as formas e funções de modo solidário, configurando-as enquanto comunicativas ou instrumentais.

\section{Os processos socioespaciais e suas relações com as formas e funções}

Os processos são ações contínuas em direção a um resultado, implicando continuidade e mudança (SANTOS, 1985, p. 50), seja no tempo ou no espaço. As ações de entendimento fundamentadas, isto é, que têm lugar no mundo (HABERMAS, 2003, t. II), por exemplo, corroboram mudanças nos processos que lhes originaram, ao passo que a sua não fundamentação implica a continuidade do processo anterior ou original.

Consoante Habermas (2003, t. II, p. 36, tradução nossa), a prática comunicativa " [...] tende a consecução, manutenção e renovação de um consenso que descansa sobre o reconhecimento intersubjetivo de pretensões de validez suscetíveis de crítica", logo, atrela-se aos processos de continuidade e mudança socioespacial no interior do mundo da vida. "Na argumentação, as pretensões de validade, pelas quais os agentes se orientam sem problemas na prática comunicacional quotidiana, são expressamente tematizadas e problematizadas" (HABERMAS, 2003, p. 155).

Esta problematização já representa a necessidade de ações na direção do entendimento mútuo entre pelo menos dois falantes, dirá Habermas (1990) e, 
do ponto de vista que nos interessa, isto é, da afirmação do indivíduo como espaço público comunicativo, um único falante, que seria ao mesmo tempo ouvinte. Problematizadas, as questões até então aproblemáticas no mundo da vida saem de seus estados de continuidade rumo à descontinuidade do discurso, próprio da interação social, e voltarão a uma forma contínua nova, ao serem fundamentadas com base no entendimento livre. As formas contínuas e descontínuas dos atos de fala expressam a estrutura interativa dos falantes e ouvintes.

Do ponto de vista das relações entre processo e forma, diferentes processos podem gerar formas semelhantes, sejam estes pretéritos ou atuais (SANTOS, 1985, p. 51). Assim, a conferência mundial sobre o meio ambiente, o Fórum Social e o Fórum Econômico são três formas semelhantes resultantes de situações passadas, no primeiro caso, e presentes, no segundo e terceiro casos. Estes espaços são formalmente semelhantes pelo arranjo entre seus atores e/ou agentes sociais, pelos processos comunicativos que os orientam em torno do entendimento sobre algo e os diferenciam por serem compostos de iguais ou desiguais falantes e ouvintes, dadas as funções opostas que garantem suas produções e reproduções.

\section{A estrutura socioespacial e sua relação com as formas, funções e os processos}

A estrutura é a inter-relação das partes de um todo ou uma dada organização (SANTOS, 1985, p. 50) das formas, incluindo o arranjo dos objetos e dos falantes e ouvintes, com suas funções mantidas pelos processos de entendimento ou de orientação ao êxito que os originam. As estruturas cognitivas ou níveis diferenciados de desenvolvimento dos atores sociais constitutivos de um dado espaço fundem-se à estrutura organizacional do arranjo de objetos e falantes e ouvintes.

"O desenvolvimento moral significa que a pessoa em crescimento transforma e diferencia de tal maneira as estruturas cognitivas já disponíveis em cada caso que ela consegue resolver melhor do que anteriormente a mesma espécie de problemas [...]" (HABERMAS, 2003, p. 155).

Tem-se dessa forma uma relação entre desenvolvimento moral e aprendizagem construtivista. A natureza comunicativa do espaço está intrinsecamente ligada ao uso intersubjetivo ou orientado para o entendimento livre da técnica, do tempo, da razão e da emoção pelo homem e pela sociedade, cuja consequência deste uso é a configuração pública das formas, funções, processos e estruturas socioespaciais. 


\section{Conclusão}

A intencionalidade produtiva e reprodutiva é uma condição fundamental para se definir o espaço como comunicativo ou público, pois os propósitos cujos fins justificam os meios não levarão senão à produção egoísta do espaço ao passo que a busca do entendimento intersubjetivo, livre de coerção, se orienta rumo à sua construção comunicativa.

O espaço é resultante das ações, como também condição de suas reproduções. Como as ações são de dois tipos, orientadas para fins e orientadas para o entendimento, os lugares ou o espaço terão suas formas, funções e processos diametralmente opostos conforme uma seja hegemônica em relação à outra.

O espaço comunicativo é composto por escalas de análise ou lugares que vão potencial ou realmente do ser humano à humanidade, passando pelos grupos, instituições sociais, empresas estatais e natureza. As famílias, as escolas e as universidades estatais, as organizações não-governamentais, as cooperativas, as associações, os fóruns globais e a Organização das Nações Unidas são exemplos, dentre tantos outros, de lugares potencialmente comunicativos.

Um espaço é comunicativo ou público não porque todos os cidadãos e cidadãs usufruem dele, ou porque a sua propriedade é coletiva. Admite-se a possibilidade e realidade de produção e reprodução de espaços comunicativos cuja propriedade é privada, a exemplo dos indivíduos, desde que estes sejam racionais, isto é, aqueles que são capazes de ao afirmarem algo, defender ou que seguindo uma norma, são capazes de justifica-la (HABERMAS, 2003, t. I, p. 33-34, tradução nossa).

Para que o espaço seja comunicativo, é necessário que ele resulte de uma produção intersubjetiva, isto é, mediante um processo democrático de entendimento sobre a produção de suas formas e funções ou formas-conteúdos (SANTOS, 1999). Estas formas e funções devem contribuir, por seu turno, para a reprodução das condições estruturais da produção que the deu origem. Isto significa que a estrutura comunicativa dos atos de fala dos atores sociais que produzem o espaço deve continuar totalizando-se.

Neste particular, é preciso diferenciar três situações. Primeiro, um espaço pode ter sido produzido publicamente, mas o seu funcionamento se dá privadamente; segundo, sua origem pode ter sido privada e, no entanto, funcionar publicamente, e terceiro, a publicidade fundamentou sua produção e baseia sua reprodução. Apenas neste último caso, é possível afirmar 
tratar-se de um espaço comunicativo, nos demais, "a esfera do público e a do privado se confundem de forma intolerável, em detrimento do indivíduo e do cidadão", como salientou Santos (2000, p. 68). Nos dois primeiros casos, entretanto, os espaços se diferenciam quanto às suas intencionalidades.

A produção e reprodução do espaço instrumental ou privado, próprio da modernidade, há de se construir outro que tenha por parâmetro a cidadania, a partir da valorização da razão e da ação comunicativas cujo conteúdo público de sua produção e reprodução se sobreponha àquele.

\section{Referências}

CARnEIRO, Rosalvo Nobre. Produção do espaço e circuitos de fluxos da indústria têxtil de São Bento-PB: do meio técnico ao meio técnico-científico-informacional. Recife: Centro de Filosofia e Ciências Humanas da Universidade Federal de Pernambuco, 2006.

A produção social pública dos lugares numa perspectiva comunicativa como contraponto à produção social privada instrumental. In: I Simpósio internacional sobre as geografias da violência e do medo: "por um espaço geográfico sem cárceres públicos ou privados". Recife. Anais... Recife: UFPE, 2007.

DURKHEIM, Émile. As regras do método sociológico. Tradução de: Pietro Nassetti. São Paulo: Martin Claret, 2003.

HABERMAS, Jürgen. Pensamento pós-metafísico: estudos filosóficos. Tradução de: Flávio Beno Siebeneichler. Rio de Janeiro: Tempo Brasileiro, 1990.

. Técnica e ciência como ideologia. Tradução de: Artur Morão. Lisboa: Edições 70, 1997.

. Consciência moral e agir comunicativo. Tradução de Guido A. de Almeida. Rio de Janeiro: Tempo Brasileiro, 2003.

Teoría de la acción comunicativa: racionalidad de la acción y racionalización social.

4. ed. Madrid: Taurus, 2003.

$\overline{\text { Taurus, }} 2003$.

Teoría de la acción comunicativa: crítica de la razón funcionalista. 4. ed. Madrid:

MARX, Karl; ENGELS, Friedrich. Manifesto do partido comunista. Tradução de: Sueli Tomazzini Barros Cassal. Porto Alegre: L\&PM, 2001.

MOREIRA, Ruy. O espaço e o contra-espaço: as dimensões territoriais da sociedade civil e do Estado, do privado e do público na ordem espacial burguesa. In: SANTOS, Milton; BECKER, Bertha (Orgs). Território, territórios: ensaios sobre o ordenamento territorial. Rio de Janeiro: DP\&A, 2006. p. 71-108.

SANTOS, Milton. Espaço e método. São Paulo: Nobel, 1985.

Metamorfoses do espaço habitado: fundamentos teóricos e metodológicos da geografia. 3. ed. São Paulo: Hucitec, 1988. 
A natureza do espaço: técnica e tempo, razão e emoção. 3. ed. São Paulo: Hucitec, 1999. O espaço do cidadão. 5. e. São Paulo: Nobel, 2000.

SARTRE, Jean-Paul. Crítica da razão dialética: precedido por Questões de método. Rio de Janeiro: DP\&A, 2002.

SMITH, Neil. Desenvolvimento desigual: natureza, capital e a produção de espaço. Tradução de: Eduardo de Almeida Navarro. Rio de Janeiro: Bertrand Brasil, 1988.

Roberto Nobre Carneiro - Doutorando do Programa de Pós-Graduação em Geografia - UFPE e professor do Departamento de Geografia/CAMEAM/UERN. 
